\title{
PENGARUH SISTEM E-BILLING DAN KUALITAS PELAYANAN TERHADAP KEPATUHAN WAJIB PAJAK
}

\author{
Rindy Citra Dewi ${ }^{1}$, Hanna Pratiwi ${ }^{2}$, Avezrima Rahmamuthi ${ }^{3}$, Berta Agus Petra ${ }^{4}$ Agung Ramadhanu $^{5}$
}

Program Studi Akuntansi, Fakultas Ekonomi dan Bisnis, Universitas Putra Indonesia "YPTK”. Jalan Raya Lubuk Begalung, Padang 25221 Indonesia

E-mail:

rindycitradewi@gmail.com

Abstrak : Penelitian ini bertujuan untuk mengetahui bagaimana Pengaruh Sistem E-Billing dan Kualitas Pelayanan dengan Pengetahuan Perpajakan sebagai variable control Terhadap Kepatuhan Wajib Pajak. Sampel pada penelitian ini diambil dengan metode incidential sampling pada wajib pajak yang sudah bekerja yang terdaftar di KPP Pratama Padang Satu.Teknik pengumpulan data yang digunakan adalah dengan menyebar kuesioner/angket kepada wajib pajak yang sudah bekerja yang terdaftar di KPP Pratama Padang Satu.Hasil penelitian ini menunjukkan bahwa Sistem E-Billing berpengaruh signifikan terhadap Kepatuhan wajib Pajak dengan nilai sig 0,000, sedangkan Kualitas Pelayanan tidak berpengaruh signifikan terhadap terhadap Kepatuhan Wajib Pajak dengan nilai sig 0,245. Dan secara bersama-sama sistem e-billing da kualitas pelayanan berpengaruh terhadap kepatuhan wajib pajak dengan nilai sig 0,000 .

Kata kunci: e-Billing, Kualitas Pelayanan, Kepatuhan Wajib Pajak

\section{Pendahuluan}

Pajak merupakan unsur penting bagi setiap negara, bahkan penting dalam rangka menopang anggaran penerimaan negara. Untuk meningkatkan penerimaan pajak, tentu diperlukan juga kerjasama dari wajib pajak, yang mana dibutuhkan kepatuhan dari wajib pajak baik pribadi maupun badan dalam melaporkan dan membayar pajak.Menurut Pratami $d k k$ (2017:2) Kepatuhan Wajib Pajak (Tax Compliance) dapat diidentifikasi dari kepatuhan Wajib Pajak dalam mendaftarkan diri, kepatuhan untuk melaporkan kembali Surat Pemberitahuan (SPT), kepatuhan dalam menghitung dan membayar pajak terhutang. Dalam pelaksanaanya, seluruh kewajiban ini berkaitan dengan pemberian pelayanan pada Wajib Pajak. Pelayanan yang diberikan kepada Wajib Pajak diharapkan dapat diberikan secara cepat, aman dan murah. Dengan adanya kemudahan ini, Wajib Pajak diharapkan dapat lebih meningkatkan kewajiban perpajakannya. Kepatuhan wajib pajak merupakan ketaatan wajib pajak untuk melakukan ketentuanketentuan atau aturan-aturan perpajakan yang diwajibkan (Noviantari dan Setiawan 2018). Adapun faktor-faktor yang mempengaruhi kepatuhan wajib pajak diantaranya yaitu : sistem e-billing dan kualitas pelayanan.
Direktorat Jenderal Pajak melakukan beberapa perubahan dalam sistem pelayanannya untuk mengikuti teknologi informasi yang berkembang di masyarakat. Direktorat Jendral Pajak meluncurkan $e$ billing untuk kemudahan pembayaran pajak secara elektronik. E-billing adalah pembayaran pajak melalui media elektronik dengan memanfaatkan kode billing sebagai kode transaksi. Transaksi pembayaran atau penyetoran pajak secara elektronik, dilakukan melalui bank atau pos persepsi dengan menggunakan kode billing. Direktorat Jendral Pajak mengemukakan bahwa manfaat dari adanya e-billing yaitu system pembayaran menjadi lebih mudah, lebih cepat dan lebih akurat. Menurut hasil penelitian (Pusparesmi, 2016), menyimpulkan bahwa penggunaan e-billing berpengaruh positif terhadap kepatuhan wajib pajak. Sistem yang menerbitkan kode billing untuk pembayaran atau penyetoran penerimaan negara secara elektronik, tanpa perlu membuat surat setoran (SPP) manual akan meningkatkan kepatuhan wajib pajak.

Pelayanan fiskus juga merupakan hal penting dalam menggali penerimaan negara dimana fiskus seharusnya melayani wajib pajak dengan jujur, professional dan bertanggungjawab tetapi faktanya para fiskus 
tidak semuanya bersih dan ada juga yang menyalahgunakan kewenangannya untuk memanipulasi data yang terkait dengan SPT wajib pajak seperti contoh kasus Dirjen Pajak memecat pegawai pajak Ambon pada tahun 2018. Hasil penelitian Susmita\& Supadimi (2016), kualitas pelayanan fiskus yang diberikan oleh petugas pelayanan pajak terhadap wajib pajak juga dapat mempengaruhi tingkat kepatuhan wajib pajak orang pribadi. Penelitian ini berfokus pada kepatuhan wajib pajak orang pribadi (WPOP) di Kantor Pelayanan Pajak Pratama Padang Satu. KPP Pratama Padang satu adalah salah satu dari 9 (sembilan) KPP di wilayah kerja Dirjen Pajak Sumbar-Jambi.

\section{Tinjauan Pustaka 2.1 Pajak}

Pajak menurut Pasal 1 ayat 1 UndangUndang Nomor 16 Tahun 2009 tentang Perubahan Keempat Atas Undang-Undang Nomor 6 Tahun 1983 Tentang Ketentuan Umum dan Tata Cara Perpajakan, disebutkan bahwa pajak adalah kontribusi wajib pajak kepada negara yang terutang oleh orang pribadi atau badan yang bersifat memaksa berdasarkan Undang-Undang, dengan tidak mendapatkan imbalan secara langsung dan digunakan untuk keperluan Negara bagi sebesar-besarnya kemakmuran rakyat. Menurut pernyataan Prof. Dr. Rochmat Soemitro,S.H. dalam Siti Resmi (2014:1) bahwa, "pajak adalah iuran peralihan kekayaan dari rakyat kepada kas Negara untuk membiayai pengeluaran rutin dan surplusnya digunakan untuk public saving yang merupakan sumber utama untuk membiayai public investment".

\subsection{Kepatuhan Wajib Pajak}

Abdul Rahman dalam Nurhidayah (2015) mengemukakan kepatuhan perpajakan dapat didefenisikan sebagai keadaan dimana wajib pajak memenuhi semua kewajiban perpajakan dan melaksanakan hak perpajakannya. Kepatuhan wajib pajak adalah pemenuhan kewajiban perpajakan yang dilakukan oleh pembayar pajak dalam rangka memberikan kontribusi bagi pembangunan negara yang diharapkan didalam pemenuhannya dilakukan secara sukarela.

\subsection{Sistem e-Billing}

e-Billing pajak menurut Direktorat Jendral Pajak (DJP) adalah sistem bayar pajak online (elektronik) dengan cara pembuatan kode billing atau ID billing terlebih dahulu. $e$ billing pajak ini hadir untuk mewujudkan komitmen DJP dalam pengalihan sistem manual menuju sistem elektronik perpajakan. Billing system merupakan serangkaian proses yang meliputi kegiatan pendaftaran peserta billing, pembuatan kode billing, pembayaran berdasarkan kode billing dan rekonsiliasi billing dalam sistem modul penerimaan negara.

\subsection{Kualitas Pelayanan}

Sistem pemungutan pajak berdasarkan self assessment yang memberikan kesempatan kepada wajib pajak untuk menghitung, membayar dan melaporkan kewajiban perpajakannya sendiri.Hal ini berarti kesadaran dan kepatuhan wajib pajak dalam memenuhi kewajiban perpajakannya berada pada wajib pajak itu sendiri.Salah satu bentuk upaya meningkatkan kepatuhan wajib pajak dapat dilakukan melalui peningkatan kualitas pelayanan. Kualitas adalah suatu kondisi dinamis yang berhubungan dengan produk, jasa manusia, proses dan lingkungan yang memenuhi atau melebihi harapan pihak yang menginginkannya. Pelayanan yang berkualitas adalah pelayanan yang dapat memberikan kepuasan kepada pelanggan serta dilakukan secara terus-menerus.

\section{Metode Penelitian \\ 3.1 Objek Penelitian}

Penelitian ini dilakukan di Kantor Pelayanan Pajak Pratama Padang Satu yang beralamat di Jalan Bagindo Azis Chan No.26, Padang Timur, Padang.Penelitian ini mencakup dalam bidang perpajakan yaitu dengan mengumpulkan jurnal-jurnal, buku-buku yang berkaitan serta melalui studi pustaka dan data primer dengan memberikan kuesioner kepada wajib pajak yang terdaftar di Kantor Pelayanan Pajak Pratama Padang Satu.

\subsection{Variabel Penelitian}


Variabel-variabel yang digunakan dalam penelitian ini adalah:

1. Variabel dependen yaitu kepatuhan wajib pajak.

2. Variabel dependen yaitu sistem $e$ billing dan kualitas pelayanan.

3. Variabel kontrol yaitu pengetahuan perpajakan.

\subsection{Sumber Data}

Sumber data dan responden dalam penelitian ini adalah data primer dan data sekunder.Data primer diperoleh dengan menyebarkan kuesioner. Dan data sekunder diperoleh seperti media massa yang mendukung dan perpustakaan.

\subsection{Populasi dan Sampel}

Populasi dalam penelitian ini adalah seluruh wajib pajak orang pribadi di KPP Pratama Padang Satu yang menggunakan e-billing dalam melakukan pembayaran pajak. Sampel dalam penelitian ini menggunakan teknik random sampling yang dipilih secara acak tanpa memperhatikan strata yang ada dalam populasi itu (Sugiyono, 2012)

\subsection{Metode Analisis Data}

Metode analisi data dalam penelitian ini menggunakan analisis regresi linear berganda. Yaitu untuk melihat sejauah mana kemampuan dari variabel independen dalam menjelaskan atau mempengaruhi variabel dependen dengan rumus :

Keterangan :

$$
\mathrm{Y}=\mathrm{a}+b_{1} X_{1}+b_{2} X_{2}+e
$$

$\mathrm{Y}=$ kepatuhan wajib pajak

$X_{1}=$ sistem e-billing

$X_{2}=$ kualitas pelayanan

\subsection{Uji Hipotesis}

Adapun pengujian hipotesis dalam penelitian ini yaitu : uji $t$, uji $F$ dan koefisien determinasi

\section{Pembahasan}

\subsection{Analisis Regreai Berganda}

Analisis regresi digunakan untuk melihat pengaruh variabel independen : sistem ebilling dan kualitas pelayanan secara simultan terhadap variable dependen : kepatuhan wajib pajak dengan dengan asumsi variable independen lain dianggap konstan.
Hasil Regresi Linear Berganda

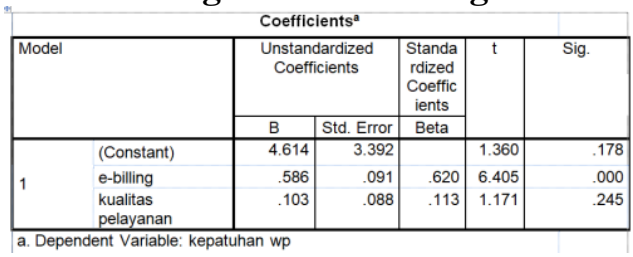

Berdasarkan tabel diatas maka dapat dilihat persamaan regresinya yaitu :

$K W P=4,614+0,586 \times 1+0,103 \times 2+e$

Dari persamaan regresi berganda di atas dapat disimpulkan bahwa :

1. Nilai konstanta sebesar 4,614 artinya jika sistem e-billing dan kualitas pelayanan diabaikan atau bernilai nol (0), maka nilai kepatuhan wajib pajak (KWP) nilainya adalah tetap sebesar 4,614.

2. Koefisien regresi variabel sistem e-billing sebesar 0,586 artinya jika sistem e-billing mengalami peningkatan satu (1) satuan dengan asumsi kualitas pelayanan diabaikan atau bernilai nol (0), maka nilai kepatuhan wajib pajak akan mengalami peningkatan sebesar 0,586.

3. Koefisien regresi variabel kualitas pelayanan sebesar 0,103 artinya jika kualitas pelayanan mengalami peningkatan satu (1) satuan dengan asumsi sistem e-billing diabaikan atau bernilai nol (0), maka kepatuhan wajib pajak akan mengalami peningkatan sebesar 0,103 .

\subsection{Uji Hipotesis}

1. Uji t

Uji t bertujuan untuk menguji pengaruh satu variabel penjelas/independen secara individual dalam menerangkan variasi variabel dependen, dengan tingkat signifikansi 0,1 (Ghozali,2011). Hasil uji t dapat dilihat tabel berikut:

\section{Tabel 4.1}


Tabel 4.2

Hasil Uji t

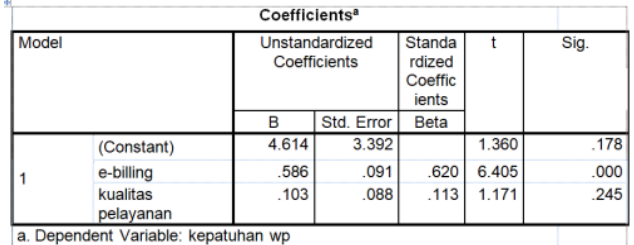

Berdasarkan tabel 4.2 hasil uji t dinyatakan bahwa:

1. Nilai variabel Sistem e-Billing (X1) thitung > t-tabel sebesar $6.405>1.663$ dan memiliki nilai sig $0,000<0,1$ maka $\mathrm{H} 1$ diterima. Hal ini menunjukkan bahwa variabel Sistem e-Billing berpengaruh terhadap Kepatuhan Wajib Pajak.

2. Nilai variabel kualitas pelayanan $(\mathrm{X} 2) \mathrm{t}$ hitung < t-tabel sebesar $1.171<1.663 \mathrm{dan}$ memiliki nilai sig 0,245>0,1 maka $\mathrm{H} 2$ ditolak. Hal ini menunjukkan bahwa variabel kualitas pelayanan tidak berpengaruh terhadap Kepatuhan Wajib Pajak.

\section{Uji F}

Uji $F$ bertujuan menunjukkan apakah dalam model regresi semua variabel independen atau bebas yang dimasukkan dalam model mempunyai pengaruh secara bersama-sama terhadap variabel dependen, yang diuji pada tingkat signifikan 0,1 (Ghozali, 2011). Hasil uji $\mathrm{F}$ dapat dilihat pada tabel berikut:

\section{Tabel 4.3}

\section{Hasil Uji F}

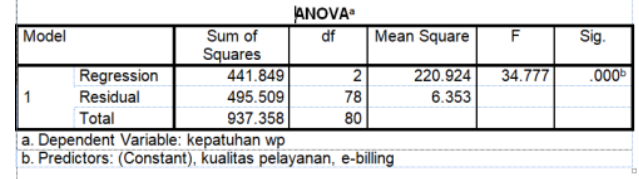

Tabel 4.3 dalam model ANOVA dapat diperoleh $\mathrm{F}$ hitung sebesar 34.777 lebih besar dari Ftabel sebesar 2.77 dengan tingkat signifikan 0,000. Oleh karena itu tingkat signifikan lebih kecil dari 0,1 maka variabel Sistem e-Billing dan kualitas pelayanan secara simultan atau bersama-sama berpengaruh signifikan terhadap variable dependen yaitu Kepatuhan Wajib Pajak.

\section{Koefisien Determinasi $\left(R^{2}\right)$}

Koefisien Determinasi (R) menunjukkan mengenai besarnya pengaruh variabel independen terhadap variabel dependen dan hasilnya disajikan pada tabel 4.26 berikut ini:

Tabel 4.4

Hasil Koefisien Determinasi

\begin{tabular}{|l|c|r|r|r|}
\hline \multicolumn{5}{|c|}{ Model Summary $^{b}$} \\
\hline Model & $R$ & R Square & Adjusted R Square & $\begin{array}{c}\text { Std. Error of the } \\
\text { Estimate }\end{array}$ \\
\hline 1 & $.687^{2}$ & \multicolumn{4}{|c|}{471} & & .458 & 2.520 \\
\hline a. Predictors: (Constant), kualitas pelayanan, e-biling \\
b. Dependent Variable: kepatuhan wp
\end{tabular}

Dari tabel 4.4 dapat dilihat bahwa koefisien determinasi (Adjust R Square) sebessar 0.458 yang berarti bahwa variabel-variabel independen mampu menerangkan kepatuhan wajib pajak sebesar 45.8\%.Sedangkan sisanya $54.2 \%$ dipengaruhi oleh faktor-faktor lain yang tidak dijelaskan dalam penelitian ini.

\section{Kesimpulan}

Berdasarkan dari hasil analisis dan pembahasan diatas, maka dapat disimpulkan bahwa yaitu :

1. Sistem e-Billing berpengaruh positif dan signifikan terhadap kepatuhan wajib pajak

2. Kualitas pelayanan tidak berpengaruh terhadap kepatuhan wajib pajak

3. .Sistem e-Billing dan kualitas pelayanan secara simultan atau bersama-sama berpengaruh signifikan terhadap kepatuhan wajib pajak

\section{DAFTAR PUSTAKA}

Direktorat Jendral Pajak. 2014. "Peraturan Direktorat Jendral Pajak Nomor PER-26/PJ/2014 Tentang Sistem Pembayaran Pajak Secara Elektronik".

Direktorat Jendral Pajak Kementerian Keuangan. 2016. E-Billing. http://www.pajak.go.id/e-billing. Dilihat pada Maret 2019.

Ghozali, Imam. 2011. "Aplikasi Analisis Multivariate Dengan Program IBM SPSS 19. Semarang: Badan Penerbitan Universitas Diponegoro. 
Handayani, Ni Putu Milan Novita dan Naniek Noviari. 2016. "Pengaruh Persepsi Manajemen Atas Keunggulan Penerapan E-Billang dan E-SPT Pajak Pertambahan Nilai Pada Kepatuhan Perpajakan". Jurnal Akuntansi Universitas Udayana, Vol 15(2): hal 1001-1028.

Mardiasmo. 2009. Perpajakan Edisi Revisi 2009. Yogyakarta: Andi Offset.

Mardiasmo. 2010. Perpajakan Edisi Revisi 2009. Yogyakarta: Andi Offset.

Mardiasmo. 2011. Perpajakan. Edisi Revisi. Yogyakarta: Andi Offset.

Mardiasmo. 2016. Perpajakan Edisi Terbaru 2016. Yogyakarta: Andi Offset.

Noviantri, Putri dan Putu Ery Setiawan. 2018. "Pengaruh Persepsi Kualitas Pelayanan, Pemahaman, Persepsi Sanksi Perpajakan, dan Lingkungan Terhadap Kepatuhan Wajib Pajak", Jurnal Akuntansi Universitas Udayana, Vol 22(3): hal 1711-1740.

Peraturan Direktur Jendral Pajak Nomor PER 26/PJ/2014 tentang Sistem Pembayaran Pajak Secara Elektronik.http://ditkeu.unair.ac.id/do wnload/PER_26_PJ_2014.pdf.

Dilihat April 2019.

Pratami, Sulindawati dan Wahyuni, 2017. "Pengaruh Penerapan E-system Perpajakan Terhadap Tingkat Kepatuhan Wajib Pajak Orang Pribadi Dalam Membayar Pajak Pada Kantor Pelayanan Pajak (KPP) Pratama Singaraja", e-Jurnal S1 Ak Universitas Pendidikan Ganesha, Vol 7, No.1.

Pusparesmi, A. 2016. "Pengaruh Penggunaan Sistem Administrasi Berbasis Internet Terhadap Tingkat Kepatuhan Wajib Pajak Orang Pribadi Pada KPP Pratama Surakarta", Skripsi Universitas Islam Batik Surakarta.

Resmi, Siti. 2011. Perpajakan: Teori dan Kasus. Jakarta: Salemba Empat.

Resmi, Siti. 2014. Perpajakan Teori dan Kasus Edisi 8. Jakarta: Salemba Empat.
Suandy, Erly. 2014. Hukum Pajak. Jakarta: Salemba Empat.

Sugiyono. 2011. Statistika Untuk Penelitian. Bandung: Alfabeta.

Sugiyono. 2012. Memahami Penelitian Kualitatif. Bandung: Alfabeta

Sugiyono. 2013. Metode Penelitian Bisnis. Bandung: Alfabeta. 